\title{
Urgences
}

\section{Pour les enfants du Vietnam... et d'ailleurs}

\section{Richard Lévesque}

Numéro 2, 3e trimestre 1981

URI : https://id.erudit.org/iderudit/025033ar

DOI : https://doi.org/10.7202/025033ar

Aller au sommaire du numéro

Éditeur(s)

Urgences

ISSN

0226-9554 (imprimé)

1927-3924 (numérique)

Découvrir la revue

Citer ce document

Lévesque, R. (1981). Pour les enfants du Vietnam... et d'ailleurs. Urgences, (2), 77-82. https://doi.org/10.7202/025033ar

Ce document est protégé par la loi sur le droit d'auteur. L'utilisation des services d’Érudit (y compris la reproduction) est assujettie à sa politique d'utilisation que vous pouvez consulter en ligne.

https://apropos.erudit.org/fr/usagers/politique-dutilisation/
Cet article est diffusé et préservé par Érudit.

Érudit est un consortium interuniversitaire sans but lucratif composé de l’Université de Montréal, l’Université Laval et l’Université du Québec à Montréal. Il a pour mission la promotion et la valorisation de la recherche. https://www.erudit.org/fr/ 


\section{RICHARD LEVESQUE}




\section{POUR LES ENFANTS DU VIETNAM... ... ET D'AILLEURS}

Vous êtes nés comme des chiens dans un pays de taille instable

Vous avez crié votre vie sans le secours de la médecine Vous avez soufflé votre souffle

Et votre cordon s'est rompu

Sous la dent pourtant peu solide et maladroite d'une aïeule Vous avez bu votre lait pauvre à une mamelle effondrée Vous avez pris votre sommeil parmi les poux d'un ventre sale Et pourtant vous avez vécu

Vous avez fait vos premiers pas dans le purin d'une ruelle Ou dans la boue d'une rizière aux cicatrices de saccage Vous avez dit vos premiers mots dans une langue bafouée Vous avez joué vos premiers jeux à la marelle des trous d'obus Vous avez ri vos premiers rires à guetter le sifflet des balles Et pourtant vous avez vécu

Vous avez volé vos repas sous le mufle des vaches maigres Vous avez couvert votre corps de quelque innommable guenille Vous avez senti chaque jour l'odeur douceâtre du sang frais Votre coeur s'est accoutumé à ne jamais se soulever Et pourtant vous avez vécu

Vous avez vécu dix années de famine de sécheresse Dix années sans savoir la pesanteur d'un ventre plein Dix années de voyage à travers la terreur

Vous avez vu mourir sans apprendre à pleurer Vous avez vu mourir vos frères chaque jour

Et vos pères et vos oncles et un jour Vous avez vu crever votre mère au soleil Vous avez vu courir les vers sur son cadavre Et les mouches par millions

Et les chiens

Et le feu 
Vous avez vu flamber vos cabanes immondes

Vous avez vu passer les hommes de la guerre Comme un fléau du ciel toujours recommencé

On vous a massacrés volés battus violés Roulés dans les débris comme débris d'ordures Et pourtant vous viviez encore

Et pourtant vous pensiez que vous étiez des hommes

Et vous vous releviez sur vos jambes galeuses

Et vos yeux se rouvraient comme des plaies de feu

Et vos bouches s'ouvraient sur des malédictions

Sans jamais prononcer les mots de l'esclavage

Mais quelle est donc la force insensée de cette race Qui voulait vivre encore dans l'enfer au napalm

Mais voilà qu'un matin c'est dans votre cou grêle Que l'acier de Pittsburgh s'est rougi brusquement C'est votre ventre énorme que visait le fusil

Ou c'est votre poitrine qu'a cognée la grenade Peu importe peu importe

C'est votre tour d'être couchés comme pantins démantelés D'avoir les tripes au soleil les doigts crispés les bras raidis $\mathrm{Ou}$ la tête roulée au bout de votre jambe

Peu importe peu importe

C'est votre jour

Et vous avez vécu dix ans comme des chiens de basse espèce Et vous mourez comme des chiens

Mais les hommes de la violence finiront bien par trébucher Sur tant et tant de morts 
Le fleuve à mes pieds pleure un peu sa plainte douce Et je suis un peu triste Et le fleuve à mes pieds gifle ou caresse un peu La roche ruisselante Je ne sais Je ne sais

Le vent me semble triste et je ne connais plus Le geste de colère ou le geste d'amour J'ai l'âme ébouriffée

Le fleuve à mes pieds roule.

Et j'ai comme un roulis dans la tête et le coeur Je suis à peu près triste Et pourtant je ne sais Je n'ai pas de raison

Je suis un fleuve triste en manque de tempêtes 
CHANSON DE MARCHE POUR LES SOLDATS QUI VONT TUER AU BOUT DU MONDE POUR DÉFENDRE LA LIBERTÉ LE BON DROIT LA DÉMOCRATIE OU N'IMPORTE QUEL AUTRE BEAU MASQUE

Du sang frais sèche sur la route

En taches noires et bourdonnantes

La guerre au moins nourrit les mouches

Camarades

La guerre au moins nourrit les mouches

Et la guerre engraisse les rats

Camarades

Les joyeux rats à gros cigares

Qui construisent des hôpitaux

Deux enfants morts baisent la route

Et des vers grouillent dans leurs yeux

Leurs yeux qui venaient de s'ouvrir

Camarades

Leurs yeux qui venaient de s'ouvrir

Et qui n'ont jamais vu la joie

Camarades

Leurs yeux qui n'ont jamais souri

Mais qui savaient pourtant pleurer

La rizière est pleine d'engrais

De bons engrais de cimetière

Et la récolte sera bonne

Camarades

$\mathrm{Oh}$ ! La récolte sera bonne

Mais le riz aura goût de sang

Camarades

Et les rats l'offriront bien sûr

Aux hôpitaux portant leur nom 
Le ciel est rouge et ma colère Saura bien planter ma chanson Jusque dans votre coeur d'acier Camarades Jusque dans votre coeur d'acier Et vous verrez les enfants morts Camarades Et vous vomirez sur les rats Jusqu'à les noyer dans leur haine. 